or that it would become commonplace. The US state of Oregon has legalized physicianassisted dying, the practice of which is meticulously monitored, and no evidence of any slippery slope has emerged. This is Lindsay's trump card - but it only argues for dying assisted by a physician, which is a problem if autonomy is the underpinning rationale for legalization.

Other topics covered include an interesting discussion of conscientious objectors in health care, the often thoroughly misinformed debate about genetically modified food, and discourses about genetic enhancement and stem-cell research. Each chapter is richly informed by factual and theoretical discussion and approached in the common-sense way that
Lindsay recommends. His use of practical examples to point out inconsistencies in arguments is vivid and gives the non-expert reader insight into these issues.

The book concludes by outlining a tentative theory of moral status. Perhaps the weakest part of the book, this reiterates how Lindsay thinks we should approach bioethical debate. We must, he argues, begin by identifying "the norms of the common morality", then "engage in a very rough weighing of the projected harms and benefits of following a proposed course of action". Then, we need to test the assumptions by examining their consequences, make them consistent and - of great importance - "understand the rationale for our norms". Lindsay does not pretend that this is easy, but he makes a good case that it is sensible and likely to be productive. Although I am less sure that such norms can be agreed, I endorse the need to think our positions through and to pay close attention to why we hold them, and the consequences of doing so. Overall, in his readable, reasoned and accessible book that challenges the taboos of bioethics, Lindsay achieves what he set out to do.

Sheila McLean is the International Bar Association Professor of Law and Ethics in Medicine at the School of Law, The University of Glasgow, Glasgow G12 8QQ, UK. She is author of Assisted Dying: Reflections on the Need for Law Reform.

e-mail: s.mclean@lbss.gla.ac.uk

\title{
Q\&A: An insider's view of the body
}

Radiologist Anders Persson of Linköping University Hospital, Sweden, reveals the body's hidden structures to clinicians by applying new techniques in magnetic resonance imaging and computed tomography to produce stunning computerenhanced three-dimensional images. The winner of the 2008 Lennart Nilsson Award for scientific photography, he tells Nature how visualization can revolutionize medicine.

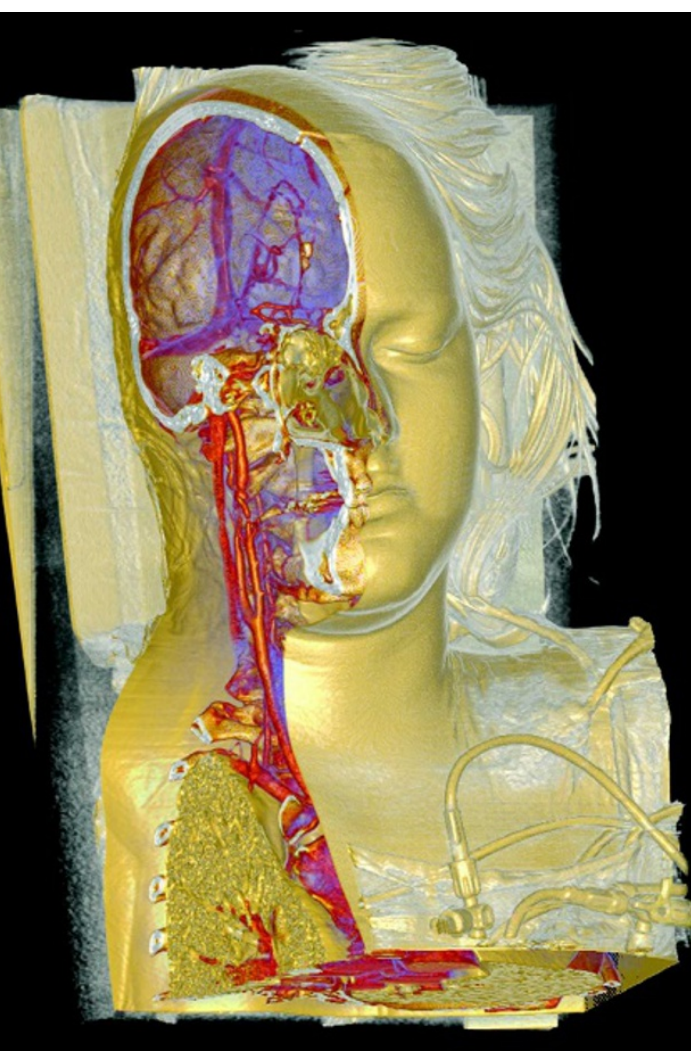

Anders Persson (right) has pioneered computerenhanced medical imaging to the benefit of patients and clinicians.

\section{What drives your work?}

Medical demand should lead technical research to the benefit of patients. I want to show the surgeon the real science, such as the true size, shape and colour of a vessel. Presenting precise and colourful details regarding the position, length and extent of aneurysms in arteries, for example, can save lives.

\section{Why are these techniques also useful for post-mortem imaging?}

Some forensic aspects, such as bone fractures, gas within wounds or metal under the skin are not visible in conventional autopsies. A virtual autopsy using threedimensional (3D) medical imaging thus provides invaluable information about the crime scene, helping to determine the cause of death and saving time.

\section{How did you become interested in medical photography?}

As a young radiologist, I realized that $3 \mathrm{D}$ and four-dimensional $\mathrm{X}$-ray visualization would rule the medical world in the future. Thirty years ago, I established a set of software functions for routine clinical use of $3 \mathrm{D}$ imaging, but it took many lectures to convince colleagues and vendors that we needed better visual tools.

\section{What are you working on today?}

I'm building a new tool called synthetic MRI, in which magnetic resonance images can be collected much more quickly for each patient. And they provide realistic values for tissue characteristics that will give a more quantitative picture of the development of pathology. I am also trying to sharpen techniques for visualizing the chemical constitution of the body, using multi-energy computed tomography.

\section{What inspires you?}

By providing beautiful images to benefit patients, I can give them vital information without scaring them. Also, the feedback I get from students stimulates me immensely to improve and explore new technical avenues.

Interview by Marta Paterlini, a writer based in Stockholm, Sweden.

e-mail: martapaterlini@nasw.org

See http://tinyurl.com/3zsclj for Anders Persson's 3D images. 